Article

\title{
Polymeric Nanoparticle-Based Photodynamic Therapy for Chronic Periodontitis in Vivo
}

\author{
Laura Marise de Freitas ${ }^{1}$, Giovana Maria Fioramonti Calixto ${ }^{2}$, Marlus Chorilli ${ }^{2}$, \\ Juçaíra Stella M. Giusti ${ }^{3}$, Vanderlei Salvador Bagnato ${ }^{3}$, Nikolaos S. Soukos ${ }^{4}$, \\ Mansoor M. Amiji ${ }^{5}$ and Carla Raquel Fontana ${ }^{1, *}$
}

1 Faculdade de Ciencias Farmaceuticas, UNESP-Univ Estadual Paulista, Campus Araraquara,

Departamento de Análises Clínicas, Araraquara, SP 14800-903, Brazil; lfmarise@gmail.com

2 Faculdade de Ciencias Farmaceuticas, UNESP-Univ Estadual Paulista, Campus Araraquara, Departamento de Farmacos e Medicamentos, Araraquara, SP 14800-903, Brazil; giovana.calixto@gmail.com (G.M.F.C.); chorilli@fcfar.unesp.br (M.C.)

3 Instituto de Fisica de Sao Carlos, Universidade de Sao Paulo, Caixa Postal 369, Sao Carlos, SP 15980-900, Brazil; jsmgiusti@gmail.com (J.S.M.G.); vander@ifsc.usp.br (V.S.B.)

4 Applied Molecular Photomedicine Laboratory, the Forsyth Institute, 245 First Street, Cambridge, MA 02142, USA; n.soukos@neu.edu

5 Department of PharmaceuticalSciences, School of Pharmacy, Bouvé College of Health Sciences, Northeastern University, 140 The Fenway, Room 156, 360 Huntington Avenue Boston, MA 02115, USA; m.amiji@neu.edu

* Correspondence: fontanacr@fcfar.unesp.br; Tel.: +55-16-3301-5727

Academic Editor: Már Másson

Received: 14 March 2016; Accepted: 4 May 2016; Published: 20 May 2016

\begin{abstract}
Antimicrobial photodynamic therapy (aPDT) is increasingly being explored for treatment of periodontitis. Here, we investigated the effect of aPDT on human dental plaque bacteria in suspensions and biofilms in vitro using methylene blue (MB)-loaded poly(lactic-co-glycolic) (PLGA) nanoparticles (MB-NP) and red light at $660 \mathrm{~nm}$. The effect of MB-NP-based aPDT was also evaluated in a clinical pilot study with 10 adult human subjects with chronic periodontitis. Dental plaque samples from human subjects were exposed to aPDT—in planktonic and biofilm phases—with MB or MB-NP $(25 \mu \mathrm{g} / \mathrm{mL})$ at $20 \mathrm{~J} / \mathrm{cm}^{2}$ in vitro. Patients were treated either with ultrasonic scaling and scaling and root planing (US + SRP) or ultrasonic scaling + SRP + aPDT with MB-NP $(25 \mu \mathrm{g} / \mathrm{mL}$ and $20 \mathrm{~J} / \mathrm{cm}^{2}$ ) in a split-mouth design. In biofilms, MB-NP eliminated approximately $25 \%$ more bacteria than free MB. The clinical study demonstrated the safety of aPDT. Both groups showed similar improvements of clinical parameters one month following treatments. However, at three months ultrasonic SRP + aPDT showed a greater effect $(28.82 \%)$ on gingival bleeding index (GBI) compared to ultrasonic SRP. The utilization of PLGA nanoparticles encapsulated with MB may be a promising adjunct in antimicrobial periodontal treatment.
\end{abstract}

Keywords: nanoparticles; PLGA; photodynamic therapy; periodontitis; methylene blue; biofilms

\section{Introduction}

Periodontitis is an inflammatory disease of the supporting tissues of the teeth caused by bacterial infection which, if left untreated, can eventually lead to tooth loss [1]. Tissue destruction occurs as a consequence of the host immune inflammatory response to oral pathogens [2]. Hundreds of different bacterial species have been isolated from periodontal pockets, and a subset of a selected number of species has been associated with periodontitis [3]. Those species participate in the formation of a biofilm on subgingival tooth surfaces in an interdependent form, where early colonizers pose 
as substrate for the adherence of species that will act as bridges between those early and the late colonizers [4].

Mechanical removal of the periodontal biofilms (scaling and root planing-SRP) remains the cornerstone of periodontal therapy. Antibiotics are also used, but they are associated with resistance concerns and poor efficacy against biofilms [5]. Another problem associated with the use of antibiotics in periodontitis is the difficulty to achieve bactericidal concentrations of the drug in the gingival crevicular fluid, for the complete eradication of pathogens [6].

One of the most promising approaches to overcome the above-mentioned drawbacks is the use of antimicrobial photodynamic therapy (aPDT). In aPDT, a photoactivated compound or photosensitizer (PS), which has been taken up by microorganisms, is activated by visible light of a specific wavelength to produce reactive oxygen species (ROS), including highly cytotoxic singlet oxygen [7]. The main advantages of aPDT over conventional antimicrobial therapies include the immediate onset of action, elimination of resistant microorganisms and secreted virulence factors, local delivery of PS, and double selectivity (deleterious effect only on sites where both PS and light are delivered concomitantly) [8]. The adjunctive use of aPDT in the treatment of periodontitis has been suggested as an alternative to chemical antimicrobial agents for elimination of subgingival species [9]. However, although it has been proven effective in a few clinical trials [10-13], aPDT beneficial effects over SRP alone are not evident in single sessions, as supported by a recent meta-analysis [14].

Several studies have shown that oral bacteria in planktonic cultures $[15,16]$ and in plaque scrapings [15,17] are susceptible to PDT. However, our previous study [18] has shown incomplete eradication of oral bacteria in biofilms-following aPDT. Several other studies have also shown incomplete destruction of oral biofilms using MB-mediated aPDT [19,20]. Biofilms exhibit reduced susceptibility not only to PDT but to antimicrobial treatments in general, which is attributed to reduced penetration of the PS and other drugs deep in the biofilm matrix [21]. In addition, it has been shown that $\mathrm{MB}$ and other phenothiazine derivatives are substrates of multidrug resistance efflux pumps in bacteria, which decreases the effectiveness of the few PS molecules that are able to penetrate the biofilm matrix [22]. Such drawbacks can be overcome by the development of drug delivery systems such as nanoparticles (NPs), which significantly improve the pharmacological characteristics of the PS, e.g., increased local retention times, improved solubility and absorption, and protection against degradation and/or efflux [23-26].

The physicochemical features of nanoparticles, such as ultra-small size, concomitantly large surface to mass ratio, and highly reactive surface, confer numerous advantages for drug delivery, especially controlling the physicochemical behavior of the drug (solubility and release), and drug targeting to the potential active site, decreasing adverse effects [27-31]. Regarding PDT, nanoparticles containing PS carry several advantages over free PS. These advantages include [32,33]: (1) a larger critical mass (concentrated package of PS) for the local production of ROS; (2) limit the target cell's ability to pump the drug back out, thus reducing the possibility of multidrug resistance; (3) increase treatment selectivity by the localized delivery of agents, which can be achieved by either passive or active targeting; and (4) the nanoparticle matrix is non-immunogenic.

Among a wide variety of NPs, polymer-based ones display a few advantages regarding drug delivery and have gained interest in PDT studies recently [34,35]. Two of the most remarkable properties of polymeric NPs are biocompatibility and low toxicity, besides their easy and straightforward process to fabricate stable formulations $[27,36]$. The most widely used polymeric NPs to date are those composed of poly(lactic-co-glycolic acid) (PLGA). PLGA's physicochemical properties, biodegradation rate, and in vivo behavior can be modified by manipulating molecular weight, lactic acid:glycolic acid ratio, and end group [37]. The biodegradable property of PLGA is due to the products of its hydrolysis, lactic acid and glycolic acid, two endogenous and easily metabolized monomers, resulting in a minimal systemic toxicity associated with the use of PLGA for drug delivery or biomaterial applications [35], which led to its approval for use in humans by the US Food and Drug Administration (FDA) and the European Medicine Agency (EMA). 
Our hypothesis is that PLGA nanoparticles can improve MB's photodynamic effects and contribute to better clinical outcomes in the treatment of chronic periodontitis. Therefore, in the present study, we investigated the effects of aPDT mediated by MB-loaded PLGA nanoparticles (MB-NP) on human dental plaque microorganisms in vitro (planktonic and biofilm phase) and in vivo (patients with chronic periodontitis).

\section{Results}

\subsection{In Vitro Studies}

In both planktonic and biofilm experiments, groups treated only with free MB, MB-NP or light did not show significant differences compared with the control group (no drug/no light), indicating an absence of toxicity for light, MB, or MB-NP alone (data not shown).

Table 1 summarizes the effects of aPDT on planktonic and biofilm species following their incubation with free MB or MB-NP. Biofilm bacteria showed greater resistance to aPDT treatment than planktonic cells. MB-MN-mediated aPDT was more effective than free MB-mediated aPDT in both planktonic and biofilm phases. MB-MN-mediated aPDT was equally effective on both planktonic and biofilm microorganisms.

In the planktonic phase, colony forming units (CFU) levels were reduced by $71 \%$ and $80 \%$ for MB-mediated and MB-NP-mediated aPDT, respectively (Figure 1). Although MB-NP-mediated aPDT exhibited greater effect on microorganisms in solution compared with free $\mathrm{MB}$, the results were not statistically significant $(p>0.05)$.

In biofilms, MB-NP-mediated aPDT exhibited 25\% greater killing effect compared with free MB (Figure 2). However, differences between the two groups were not statistically significant $(p>0.05)$.

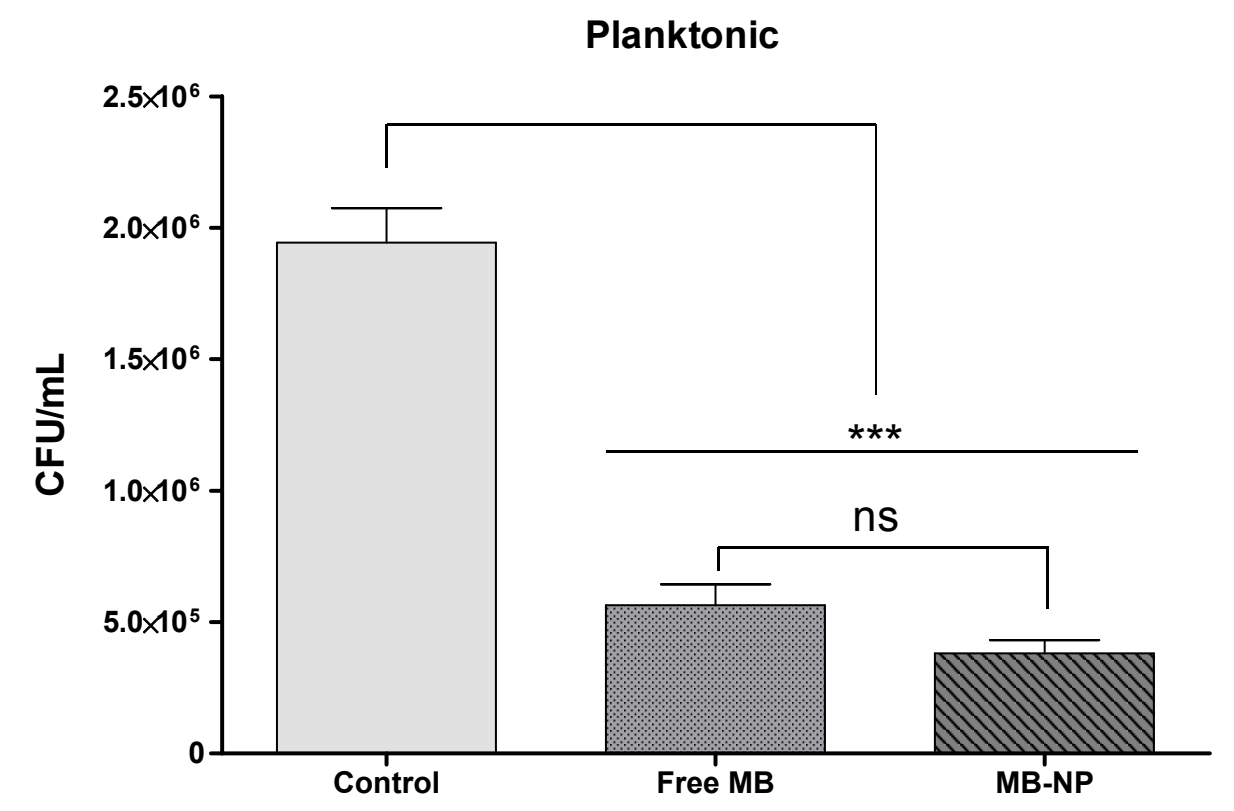

Figure 1. Recovered $\mathrm{CFU} / \mathrm{mL}$ after antimicrobial photodynamic therapy (aPDT) treatment of planktonic bacteria with free methylene blue (MB) $(25 \mu \mathrm{g} / \mathrm{mL})$ and MB-NP $(25 \mu \mathrm{g} / \mathrm{mL}$ equivalent to $\mathrm{MB}$ ) and visible light at $660 \mathrm{~nm}$ with an energy fluence of $20 \mathrm{~J} / \mathrm{cm}^{2}$. Each bar is the mean values of the means from 10 samples (data from each sample were representative of four independent suspensions). Error bars denote the standard deviation of the mean. The asterisks represent the statistical difference between the groups and the control (one-way ANOVA with Tukey's post hoc). ${ }^{* * *} p<0.001$; ns: not significant; MB: methylene blue; MB-NP: MB-loaded PLGA nanoparticles; CFU: colony forming units. 
Table 1. Effects of antimicrobial photodynamic therapy (aPDT) on planktonic and biofilm species in vitro.

\begin{tabular}{ccc}
\hline Planktonic & Free MB & MB-NP \\
\hline $\log _{10}$ steps reduction & 0.58 & 0.71 \\
$\%$ reduction & 70.97 & 80.40 \\
CFU /mL average & 564,167 & 380,833 \\
$\log _{10}$ average & 5.70 & 5.58 \\
SD & 0.21 & 0.20 \\
\hline Biofilm & Free MB & MB-NP \\
\hline $\log _{10}$ steps reduction & 0.35 & 0.69 \\
$\%$ reduction & 55.04 & 79.37 \\
CFU /mL average & $1,002,500$ & 972,500 \\
$\log _{10}$ average & 6.00 & 5.99 \\
SD & 0.17 & 0.22
\end{tabular}

Subgingival plaque samples from 10 patients were assayed either in planktonic phase or biofilms ( $n=12$ replicates). Experimental groups (control, MB in solution, and MB in PLGA nanoparticles) were compared via one-way ANOVA followed by Tukey's post hoc. MB: methylene blue; SD: standard deviation; CFU: colony forming units.

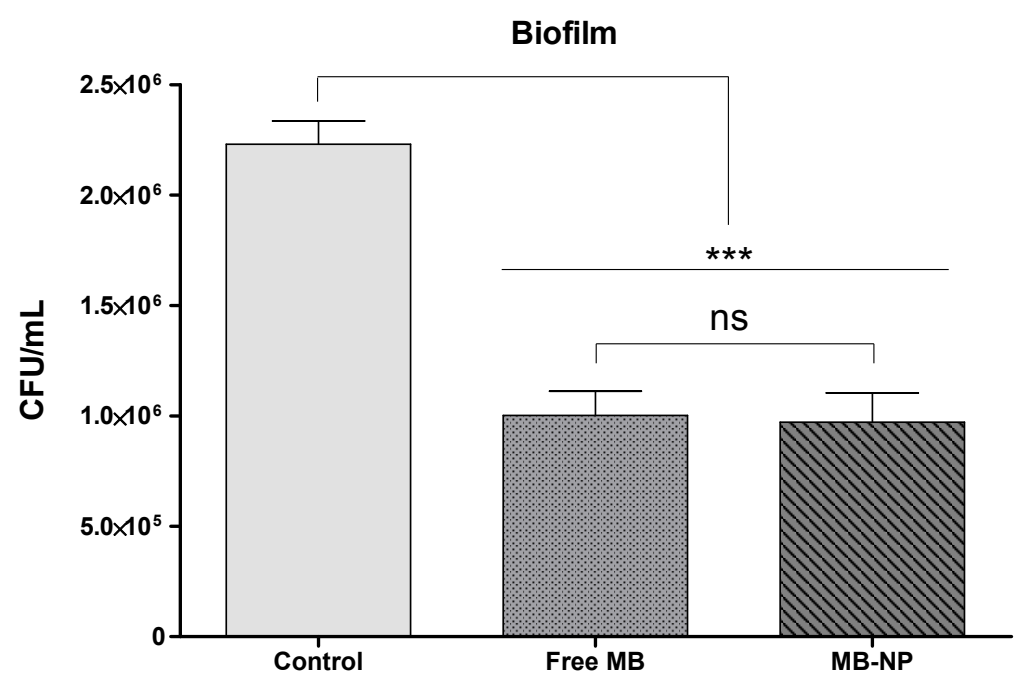

Figure 2. Recovered $\mathrm{CFU} / \mathrm{mL}$ after aPDT treatment of bacteria growing in biofilms with free MB $(25 \mu \mathrm{g} / \mathrm{mL})$ and MB-NP $(25 \mu \mathrm{g} / \mathrm{mL}$ equivalent to $\mathrm{MB})$ and visible light at $660 \mathrm{~nm}$ with an energy fluence of $20 \mathrm{~J} / \mathrm{cm}^{2}$. Each bar is the mean values of the means from 10 samples (data from each sample were representative of four independent biofilms). The asterisks represent the statistical difference between the groups and the control (one-way ANOVA with Tukey's post hoc). ${ }^{* * *} p<0.001$; ns: not significant; MB: methylene blue; MB-NP: MB-loaded PLGA nanoparticles; CFU: colony forming units.

\subsection{In Vivo Study}

After treatments, both groups exhibited a trend of a reduction of moderate and deep sites (Figure 3). Results were more evident at one month, with a tendency to return to baseline levels by three months after treatments in both groups. Ultrasonic scaling (US) + SRP associated with aPDT had a slightly better outcome than US + SRP alone $(p=0.0298)$.

Visible plaque index (VPI) was similar for both groups at all time points, with no statistically significant difference observed (Figure $4 \mathrm{a} ; p=0.9299$ ). After three months, there was a tendency of returning to baseline levels, as noticed for probing pocket depth (PPD). Gingival bleeding index (GBI) percentages decreased drastically and similarly for both groups by one month after treatment (Figure $4 \mathrm{~b} ; p=0.4571)$. Nonetheless, US + SRP + aPDT had a better performance $(28.82 \%)$ in preventing GBI compared to US + SRP at three months. 


\section{Probing pocket depth (PPD) moderate to deep sites}

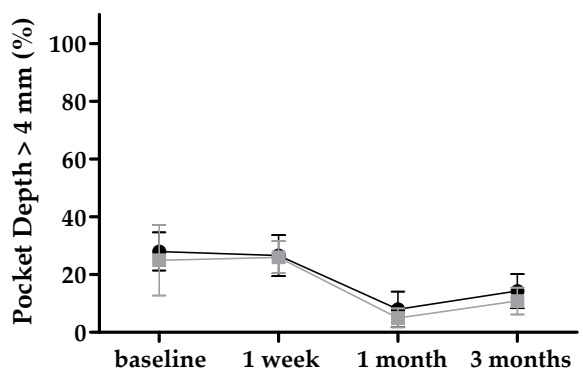

US+SRP

US+SRP+aPDT

Figure 3. Probing pocket depths. Probing was accessed at baseline, one week, one month, and three months after treatments. Shapes represent mean values from 10 patients at each time point. Error bars represent the standard deviation. US + SRP: ultrasonic scaling and scaling and root planing; US + SRP + aPDT: US + SRP followed by antimicrobial photodynamic therapy.

Visible plaque index (VPI)

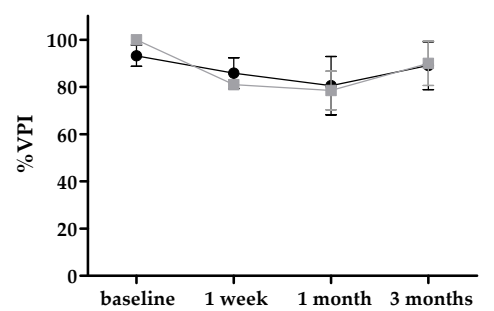

(a)
Gingival bleeding index (GBI)

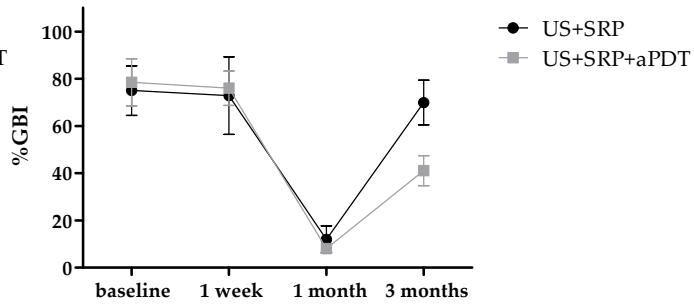

(b)

Figure 4. Visible plaque and Gingival bleeding indexes. VPI (a) and GBI (b) scores were accessed at baseline, one week, one month, and three months after treatments. Shapes represent mean values from 10 patients at each time point. Error bars represent the standard deviation. US + SRP: ultrasonic scaling and scaling and root planing; US + SRP + aPDT: US + SRP followed by antimicrobial photodynamic therapy.

The percentage of sites with bleeding on probing (BOP) decreased significantly in both groups one month after treatments, with US + SRP + aPDT group being statistically more effective in reducing BOP than US + SRP (Figure 5a; $p=0.0229$ ). Clinical attachment level (CAL) level was sustained in both groups through all time points with no statistical differences between them (Figure $5 b ; p=0.7826$ ).

Bleeding on probing (BOP)

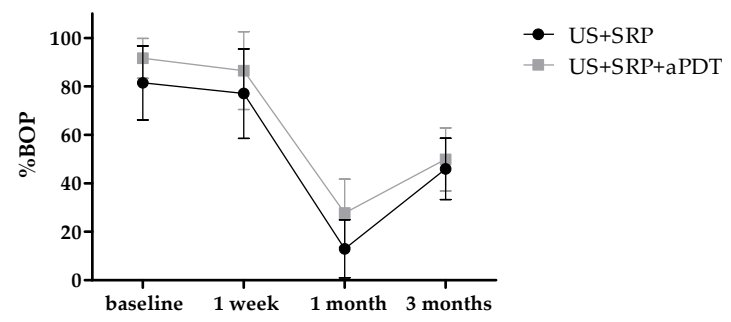

(a)
Clinical attachment level (CAL)

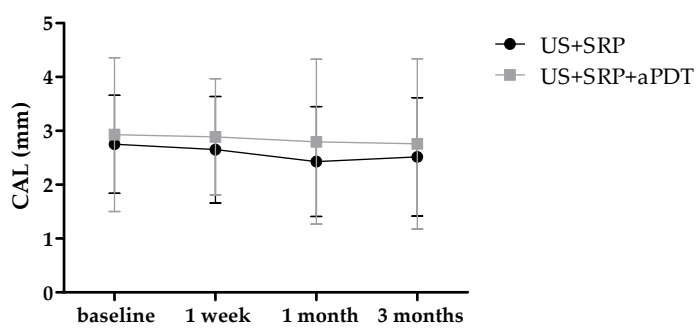

(b)

Figure 5. Bleeding on probing and Clinical attachment level. BOP (a) and CAL (b) scores were accessed at baseline, one week, one month, and three months after treatments. Shapes represent mean values from 10 patients at each time point. Error bars represent the standard deviation. US + SRP: ultrasonic scaling and scaling and root planing; US + SRP + aPDT: US + SRP followed by antimicrobial photodynamic therapy. 
Overall, except for CAL, all clinical parameters had an improvement at one month for both treatments.

\section{Discussion}

Recent meta-analyses on the effect of aPDT for periodontitis showed that the use of aPDT as an adjunct to SRP did not yield better results than SRP alone or associated with systemic antibiotics [38] or provided short-term benefits [39] when administrated as a single session. When applied in multiple sessions, however, aPDT has been proven safe and effective as an adjunctive therapy in periodontal disease treatment, as evidenced by a plethora of studies [10-13]. Several antimicrobial resistance mechanisms may be responsible for the reduced susceptibility of dental plaque to aPDT. These include the expression of certain phenotypes by biofilm species [40], the slow growing or starved state of microorganisms within biofilms [41], the inactivation of PS [42], the presence of multidrug resistance pumps in bacterial cells that expel the PS [43], and the restricted penetration of PS in oral biofilms [44]. The treatment of biofilm-associated bacterial infections poses challenges due to several antimicrobial resistance mechanisms of biofilms [45]. Possible explanations for the reduced susceptibility of dental plaque to aPDT include one way to overcome the incomplete eradication of dental plaque microorganisms is to develop a delivery system that significantly improves the pharmacological characteristics of the PS.

In the present study, our hypothesis was that MB-loaded PLGA nanoparticles would exhibit a superior photodynamic effect on human dental plaque bacteria-in planktonic and biofilm phase-compared with free MB. Additionally, a pilot study was conducted with 10 patients to evaluate the efficacy of aPDT with MB-NP on chronic periodontitis as an adjunct to ultrasonic scaling and SRP. This is the first in vivo study that employed the use of polymeric nanoparticles as carriers of PS for aPDT. PLGA nanocarriers have been used successfully in drug delivery of MB in vitro, previously [33,46]. MB lacks its photochemical properties when it is encapsulated in PLGA and regains its phototoxicity when it is released by PLGA [47].

In suspensions, the synergism of light and MB-NP showed a greater killing effect $(80.5 \%)$ over free $\mathrm{MB}(71 \%)$. In oral microcosm laboratory biofilms, nanoparticles and free MB reduced bacterial viability by $79 \%$ and $55 \%$, respectively. Although, differences between aPDT groups in both planktonic and biofilm phase were not statistically significant, photodynamic killing results were similar in all experiments. The greater photodynamic effect of MB-loaded nanoparticles over free MB in suspensions and biofilms was also demonstrated by Klepac-Ceraj et al. (2011) [46]. However, in the present study the effect of aPDT on both planktonic and biofilm microorganisms was almost the same; $80.5 \%$ vs. $79 \%$, respectively. These data show that nanoparticles were able to penetrate the biofilm and target microorganisms rapidly. Our findings are supported by recent studies that have demonstrated that nanoparticles, regardless their composition, can successfully disrupt the biofilm matrix, allowing for a deeper penetration and a sustained release of drugs [48-51], as well as increasing drug stability and retention [52-55].

Our clinical pilot study clearly demonstrated the safety of aPDT. No adverse effects were reported. In this study, the effect of aPDT as an adjunct to US and SRP was compared to US and SRP alone. All clinical parameters (VPI, GBI, BOP, and PPD) in both groups showed the greatest improvement one month following treatment with the exception of CAL that was sustained in both groups through all time points. After one month, all parameters showed a similar increasing trend. At all time points, there were no statistically significant differences between the two treatment groups. However, at three months US + SRP + aPDT showed a greater effect $(28.82 \%)$ on GBI compared to US + SRP.

At three months after treatment all clinical parameters started to return to baseline levels, for both US + SRP and US + SRP + aPDT, which indicates bacterial recolonization of periodontal pockets. Treatment rebound due to bacterial recolonization is a common feature of chronic periodontitis treatments, regardless the technique employed, as evidenced by studies of Petersilka [56], Zijnge [57], Teles [58], and Sanz-Sánchez [59]. However, the studies of Novaes Jr [60] and Petelin [61] demonstrate 
that different groups of bacteria are affected after treatment with aPDT or SRP, resulting in a distinct pattern of recolonization. In fact, aPDT was more effective in reducing the presence of Red Complex species, such as Tanerella forsythia and Treponema denticola, and Aggregatibacter actinomycetemcomitans, a species known by its association with localized aggressive periodontitis [60,61]. Taken together, those findings highlight that the association of classical SRP to aPDT in the treatment of periodontitis sums up benefits.

Our findings suggest that MB-NP have the potential to be used as carriers of MB for photodynamic inactivation of dental plaque bacteria. MB-NP and light exhibited a greater killing in biofilms. Our hypothesis is that MB-NP were able to diffuse and released MB within biofilms. This may not be the case in the clinical pilot study that comprised a small number of patients, and, therefore, restricts any broader conclusions. Future studies should define the appropriate aPDT dosimetry (MB concentration, incubation time, power density, and energy fluence) for effective elimination of biofilm species. The possibility of multiple applications of aPDT should also be explored. These improvements and changes in the treatment protocol may demonstrate the adjunctive benefit of aPDT in periodontitis.

\section{Materials and Methods}

\subsection{Subjects and Samples}

Forty-seven patients were analyzed, 27 were excluded due to one or more exclusion criteria, and 20 patients entered the study. Ten patients were assigned to in vitro assays and ten patients participated in the in vivo study. All subjects gave their informed written consent to donate dental samples for inclusion before they participated in the study. The study was conducted at the Dental Office of University of Sao Paulo (Optics Group-Instituto de Fisica de Sao Carlos, Sao Carlos, SP 15980-900, Brazil), and conducted in accordance with the Declaration of Helsinki, and the protocol was approved by the Dental School Research Ethics Committee at Araraquara, UNESP Univ. Estadual Paulista (Protocol \#04/11). The in vivo study was approved by Human Research Committee-Process HCRP $\mathrm{n}^{\circ} 1857 / 2008$. Patients completed a health history questionnaire to ensure that they were medically qualified for participation in the study. Inclusion criteria for the study were patients diagnosed with chronic periodontitis [62] who were no smokers, had at least four teeth in each quadrant (16 teeth on their functional dentition, excluding third molars) and had, at least, two posterior teeth with pocket depth $\geqslant 4 \mathrm{~mm}$ and bleeding on probing (BOP). The exclusion criteria were: smokers, orthodontic brackets, pregnancy, diabetes mellitus, use of anti-inflammatory or antibiotic agents within the previous three months, periodontal therapy during the six months prior to sampling, or use of any medications associated with the gingival disease. The deepest pockets $(>5 \mathrm{~mm})$ of each quadrant were used for plaque sampling after the photodynamic and/or periodontal procedure.

\subsection{In Vitro Study-Sample Collection}

Using individual sterile Gracey curettes, dental plaque samples from subgingival sites were taken in each subject (five to eight samples per subject; pockets $>5 \mathrm{~mm}$ ) and placed immediately into pre-reduced, anaerobically sterilized Ringer's solution (Anaerobe Systems, Morgan Hill, CA, USA), forming a sample pool. Bacteria from the plaque samples were dispersed by sonication and homogenezation through Pasteur pipettes. The optical density of the bacterial suspensions was measured in a spectrophotometer and then the pool sample from the ten subjects was divided into two parts, for planktonic and biofilm assays.

\subsection{Preparation of Enriched Agar Plates}

Blood agar enriched with hemine, menadione, and $\mathrm{N}$-acetylmuramic acid was prepared. Medium composition comprised 5\% defibrinated sheep blood (NewProv LTDA, Pinhais, PR, Brasil), $2.6 \%$ brain heart infusion agar (BHI-Difco Laboratories, Detroit, MI, USA), 2\% trypticase soy agar (TSA—Difco (Franklin Lakes, NJ, USA)), 1\% yeast extract (BBL, Cockeysville, MD, USA), 1\% hemine 
(Sigma Chemical Co., St. Louis, MO, USA), $1 \% \mathrm{~N}$-acetylmuramic acid (Sigma Chemical Co.), and 0.5\% menadione (Sigma Chemical Co.). Agar mixture was sterilized in autoclave and, after cooling it to $50{ }^{\circ} \mathrm{C}$, sheep blood, menadione, and $\mathrm{N}$-acetylmuramic acid were added to the mixture under aseptic conditions. Medium was then dispensed into 96-well plates (TPP, Zellkultur testplatte, Trasadingen, Switzerland), $150 \mu \mathrm{L}$ per well, and allowed to solidify. Plates were stored at $4{ }^{\circ} \mathrm{C}$.

\subsection{Development of Plaque-Derived Biofilms}

For biofilm development, the bacterial inoculum (in BHI broth) was adjusted to contain approximately $10^{7}$ cells $/ \mathrm{mL}$. Approximately $1.5 \times 10^{6}$ bacteria $(150 \mu \mathrm{L})$ were dispensed into a blood agar well. For each experimental group 4 wells were used. Plates were incubated at $35^{\circ} \mathrm{C}$ in anaerobic atmosphere $\left(80 \% \mathrm{~N}_{2}, 10 \% \mathrm{H}_{2}\right.$, and $\left.10 \% \mathrm{CO}_{2}\right)$ for seven days. At day 2 the broth was carefully aspirated and fresh $\mathrm{BHI}$ broth was added to each well. Then, fresh BHI broth was added daily to each well, very slowly, to avoid disruption of the biofilm.

\subsection{Photodynamic Treatment in Vitro}

A diode laser with a central wavelength of $660 \mathrm{~nm}$ coupled to a $1 \mathrm{~mm}$ optical fiber that delivered light into a lens was used for both planktonic and biofilm studies. The system formed a uniform circular spot, $2 \mathrm{~cm}$ in diameter, which was able to irradiate a group of four wells in a 96-well plate each time, from above, at room temperature in the absence of surrounding light. The power density was measured using a powermeter. For both planktonic and biofilm experiments power density was $100 \mathrm{~mW} / \mathrm{cm}^{2}$ and energy fluence was $20 \mathrm{~J} / \mathrm{cm}^{2}$. Microorganisms in planktonic and biofilm phase were exposed only once to light. Free $\mathrm{MB}$ concentration was $25 \mu \mathrm{g} / \mathrm{mL}$ and the final concentration of MB-NP was $25 \mu \mathrm{g} / \mathrm{mL}$ equivalent to MB. Experimental groups were: (1) no light/no PS (CONTROL); (2) treated only with free MB; (3) treated only with MB-NP; (4) treated only with light; (5) treated with light and free MB; and (6) treated with light and MB-NP.

\subsubsection{Planktonic Bacteria}

Aliquots of bacterial suspensions $\left(10^{8}\right.$ cells $\left./ \mathrm{mL}\right)$ were placed in sterile microtubes and centrifuged at $7000 \mathrm{rpm}$ for $4 \mathrm{~min}$. One milliliter of sterile free MB or MB-NP was then added after discarding the supernatants. Bacterial cells were suspended in free MB or MB-NP and placed in four wells of 96-well plates for $10 \mathrm{~min}$ before exposure to light. Following aPDT, bacterial suspensions underwent serial dilutions in $\mathrm{BHI}$ broth, and $100 \mu \mathrm{L}$ aliquots were plated on blood agar and incubated under anaerobic conditions at $35^{\circ} \mathrm{C}$ for seven days prior to CFU scoring.

\subsubsection{Biofilms}

Carefully, growth medium was aspirated from each well of 96-well plates and replaced by $150 \mu \mathrm{L}$ of sterile free MB or MB-NP. Biofilms were then incubated for $10 \mathrm{~min}$ followed by exposure to light. After aPDT, bacteria from each well were gently scraped using a sterile bacteriological loop, dispersed in $\mathrm{BHI}$ broth and measured in a spectrophotometer at $600 \mathrm{~nm}$. After, serial dilutions were prepared and $100 \mu \mathrm{L}$ aliquots were plated on blood agar plates, which were incubated anaerobically at $35^{\circ} \mathrm{C}$ for seven days prior to CFU counting.

\subsection{Preparation and Characterization of PLGA Nanocarriers}

MB loaded into PLGA nanoparticles $(10 \% w / w)$ were prepared in the Department of Pharmaceutical Sciences at Northeastern University as previously described [33]. Briefly, a PLGA (76 mg) and Pluronic ${ }^{\circledR}$ F-108 (14 mg) solution was prepared in $5 \mathrm{~mL}$ of acetone. MB as oleate salt (Sigma Chemicals Co.) was dissolved at 10\% $(w / w)$ concentration in the PLGA acetone solution for the preparation of the MB-loaded nanoparticles. To insure that the formed nanoparticles have a stable hydrophilic surface, which resists aggregation, pluronic triblock copolymers were added to the polymer 
solution in acetone at $20 \%(w / w)$. The acetone solution was added into an aqueous $(50 \mathrm{~mL})$ solution under vigorous stirring and left to stir overnight. The following day, nanoparticles were centrifuged at 10,000 rpm for $20 \mathrm{~min}$, washed twice with deionized distilled water and lyophilized. Data regarding nanoparticle characterization were previously published [33]. Figure 6 shows a scanning electron micrograph of blank PLGA nanoparticles.

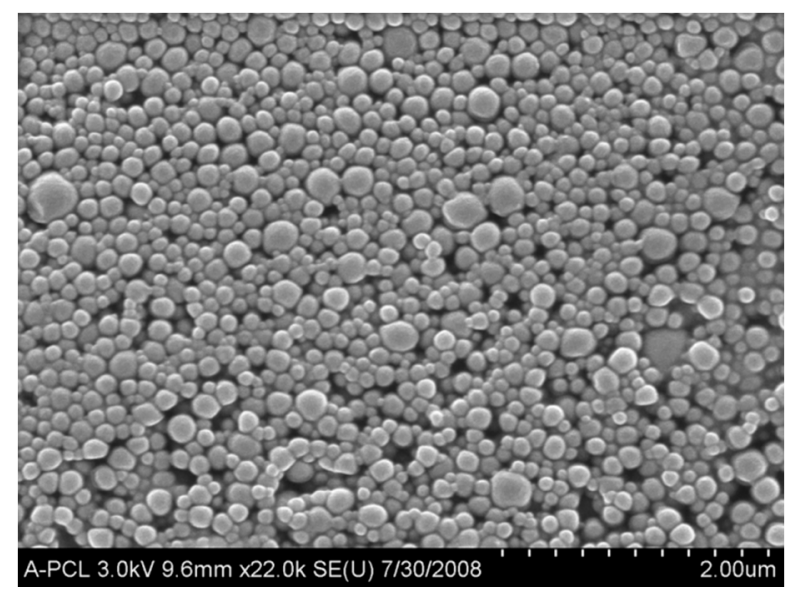

Figure 6. Scanning electron micrograph (SEM) of PLGA nanoparticles. Figure shows an SEM image of higher magnification with spherical nanoparticles of 150-250 nm in diameter.

\subsection{In Vivo Study}

This 3-month study evaluated clinically the effectiveness of the adjunctive use of polymeric nanoparticle-based aPDT following periodontal instrumentation with ultrasonic scaling and mechanical scaling and root planing (SRP) in patients (seven men; 13 women; aged 20-70) with moderate to advanced chronic periodontitis [62]. All enroled patients completed the study. The study investigated the correlation of the clinical parameters before and after aPDT treatment in periodontitis sites in the same patient, following a split-mouth design. All four quadrants received treatment. Two of them (one lower and one upper jaw) received non-PDT ultrasonic scaling followed by mechanical SRP with Gracey curettes and the other two quadrants received ultrasonic scaling (US) and mechanical SRP followed by aPDT. Prior to aPDT, MB-NP were applied as a mouthwash (MB-NP dispersed in PBS $1 \times$ ) and then periodontal pockets were irrigated with the same PS solution for $10 \mathrm{~min}$. PDT was applied as a single session. The effect of the two different treatment groups-US + SRP $v s$. $\mathrm{US}+\mathrm{SRP}+\mathrm{aPDT}$ - was investigated on clinical parameters such as probing pocket depth (PPD), visible plaque index (VPI), gingival bleeding index (GBI), bleeding on probing (BOP), and clinical attachment level (CAL). All clinical parameters measured at baseline, one week, one month, and three months, and recorded by a single examiner. Oral hygiene procedures were instructed and reinforced at every appointment. PPD at baseline was divided into two categories: shallow sites (pocket depth from 1 to $3 \mathrm{~mm}$ ) and moderate to deep sites (moderate: $4-6 \mathrm{~mm}$; deep $\geqslant 7 \mathrm{~mm}$ ).

\subsection{Data Collection-Measurement Reproducibility}

Calibration trials were performed prior to the study to ensure adequate intra-examiner reproducibility (kappa statistic $\geqslant 90 \%$ ). Intra-examiner kappa values were 0.97 (PPD) and 0.93 (CAL). All measurements were performed by a single examiner using a standard University of North Carolina probe with millimeter markings.

\subsection{Clinical Parameters}

Clinical parameters that were examined in this study included presence or absence of visible plaque index (VPI), gingival bleeding index (GBI), and bleeding on probing (BOP). Full-mouth probing 
pocket depth (PPD) and clinical attachment level (CAL) were measured by a North Carolina manual periodontal probe (North Caroline Probe, Hu-Friedy, Chicago, IL, USA) at six sites per tooth in all teeth except third molars, at baseline, one week, one month, and three months after the aPDT and non-aPDT associated with ultrasonic scaling and periodontal treatment (US-SRP).

\subsection{Statistical Analysis}

In vitro data were expressed as the mean plus standard deviation (SD) and were analyzed by one-way ANOVA with Tukey's post hoc test using GraphPad Prism ${ }^{\circledR}$ Version 5.01 software (GraphPad Software Inc., La Jolla, CA, USA). Differences were considered to be significant when $p<0.05$ (confidence level of 95\%). For in vivo data, differences between groups were sought using the repeated measures $t$-test, also using GraphPad Prism ${ }^{\circledR}$ Version 5.01 software. Differences with a $p$-value $<0.05$ at a confidence level of $95 \%$ were considered significant.

Acknowledgments: Financial support from FAPESP 2012/21203-4 (Fundação de Amparo a Pesquisa do Estado de São Paulo) is gratefully acknowledged.

Author Contributions: Carla Raquel Fontana and Juçaíra Stella M. Giusti conceived and designed the experiments; Carla Raquel Fontana performed the experiments; Laura Marise de Freitas and Juçaíra Stella M. Giusti analyzed the data; Marlus Chorilli and Vanderlei Salvador Bagnato contributed with materials and analysis tools; tLaura Marise de Freitas wrote the paper; Mansoor M. Amiji provided the nanoparticles; Nikolaos S. Soukos, Giovana Maria Fioramonti Calixto, Marlus Chorilli and Carla Raquel Fontana contributed in writing and critically corrected the manuscript. All authors read and approved the final manuscript.

Conflicts of Interest: The authors declare no conflict of interest.

\section{Abbreviations}

$\begin{array}{ll}\text { aPDT } & \begin{array}{l}\text { antimicrobial photodynamic therapy } \\ \text { bOP }\end{array} \\ \text { CFU } & \begin{array}{l}\text { colony-forming unity } \\ \text { clinical attachment level }\end{array} \\ \text { CAL } & \text { gingival bleeding index } \\ \text { GBI } & \text { methylene blue } \\ \text { MB } & \text { methylene blue-loaded PLGA nanoparticles } \\ \text { MB-NP } & \text { nanoparticle } \\ \text { NP } & \text { poly(Lactic-co-Glycolic Acid) } \\ \text { PLGA } & \text { probing pocket depth } \\ \text { PPD } & \text { reactive oxygen species } \\ \text { ROS } & \text { scaling and root planing } \\ \text { SRP } & \text { visible plaque index } \\ \text { VPI } & \end{array}$

\section{References}

1. Zuzanna, O.; Łabuzemail, P.; Macykemail, W.; Chomyszyn-Gajewskaemail, M. Antimicrobial photodynamic therapy-A discovery originating from the pre-antibiotic era in a novel periodontal therapy. Photodiagn. Photodyn. Ther. 2015, 12, 612-618. [CrossRef]

2. Lin, J.; Bi, L.; Yu, X.; Kawai, T.; Taubman, M.A.; Shen, B.; Han, X. Porphyromonas gingivalis exacerbates ligature-induced, RANKL-dependent alveolar bone resorption via differential regulation of Toll-like receptor 2 (TLR2) and TLR4. Infect. Immun. 2014, 82, 4127-4134. [CrossRef] [PubMed]

3. Hajishengallis, G. Periodontitis: From microbial immune subversion to systemic inflammation. Nat. Rev. Immunol. 2015, 15, 30-44. [CrossRef] [PubMed]

4. Guthmiller, J.M.; Novak, K.F. Periodontal Diseases (chapter 8). In Polymicrobial Diseases; Brogden, K.A., Guthmiller, J.M., Eds.; ASM Press: Washington, DC, USA, 2002.

5. Cieplik, F.; Tabenski, L.; Buchalla, W.; Maisch, T. Antimicrobial photodynamic therapy for inactivation of biofilms formed by oral key pathogens. Front. Microbiol. 2014, 5, 1-17. [CrossRef] [PubMed]

6. Nguyen, S.; Hiorth, M. Advanced drug delivery systems for local treatment of the oral cavity. Ther. Deliv. 2015, 6, 595-608. [CrossRef] [PubMed]

7. Allison, R.R.; Moghissi, K. Photodynamic therapy (PDT): PDT mechanisms. Clin. Endosc. 2013, 46, 24-29. [CrossRef] [PubMed] 
8. Dai, T.; Huang, Y.-Y.; Hamblin, M.R. Photodynamic therapy for localized infections—State of the art. Photodiagn. Photodyn. Ther. 2009, 6, 170-188. [CrossRef] [PubMed]

9. Haag, P.A.; Steiger-Ronay, V.; Schmidlin, P.R. The in vitro Antimicrobial Efficacy of PDT against Periodontopathogenic Bacteria. Int. J. Mol. Sci. 2015, 16, 27327-27338. [CrossRef] [PubMed]

10. Sreedhar, A.; Sarkar, I.; Rajan, P.; Pai, J.; Malagi, S.; Kamath, V.; Barmappa, R. Comparative evaluation of the efficacy of curcumin gel with and without photo activation as an adjunct to scaling and root planing in the treatment of chronic periodontitis: A split mouth clinical and microbiological study. J. Nat. Sci. Biol. Med. 2015, 6, S102-S109. [CrossRef] [PubMed]

11. Moreira, A.L.; Novaes, A.B., Jr.; Grisi, M.F.; Taba, M., Jr.; Souza, S.L.; Palioto, D.B.; de Oliveira, P.G.; Casati, M.Z.; Casarin, R.C.; Messora, M.R. Antimicrobial photodynamic therapy as an adjunct to non-surgical treatment of aggressive periodontitis: A split-mouth randomized controlled trial. J. Periodontol. 2015, 86, 376-386. [CrossRef] [PubMed]

12. Alwaeli, H.A.; Al-Khateeb, S.N.; Al-Sadi, A. Long-term clinical effect of adjunctive antimicrobial photodynamic therapy in periodontal treatment: A randomized clinical trial. Lasers Med. Sci. 2015, 30, 801-807. [CrossRef] [PubMed]

13. Campanile Müller, V.S.; Giannopoulou, C.; Campanile, G.; Cancela, J.A.; Mombelli, A. Single or repeated antimicrobial photodynamic therapy as adjunct to ultrasonic debridement in residual periodontal pockets: Clinical, microbiological, and local biological effects. Lasers Med. Sci. 2015, 30, 27-34. [CrossRef]

14. Azarpazhooh, A.; Shah, P.S.; Tenenbaum, H.C.; Goldberg, M.B. The effect of photodynamic therapy for periodontitis: A systematic review and meta-analysis. J. Periodontol. 2010, 81, 4-14. [CrossRef] [PubMed]

15. Radcliffe, C.E.; Potouridou, L.; Qureshi, R.; Habahbeh, N.; Qualtrough, A.; Worthington, H.; Drucker, D.B. Antimicrobial activity of varying concentrations of sodium hypochlorite on the endodontic microorganisms Actinomyces israelii, A. naeslundii, Candida albicans and Enterococcus faecalis. Int. Endod. J. 2004, 37, 438-446. [CrossRef] [PubMed]

16. Araújo, N.C.; Araújo, N.C.; Fontana, C.R.; Bagnato, V.S.; Gerbi, M.E. Photodynamic effects of curcumin against cariogenic pathogens. Photomed. Laser Surg. 2012, 30, 393-399. [CrossRef]

17. Harris, F.; Chatfield, L.K.; Phoenix, D.A. Phenothiazinium based photosensitisers-photodynamic agents with a multiplicity of cellular targets and clinical applications. Curr. Drug Targets 2005, 6, 615-627. [CrossRef] [PubMed]

18. Fontana, C.R.; Abernethy, A.D.; Som, S.; Ruggiero, K.; Doucette, S.; Marcantonio, R.C.; Boussios, C.I.; Kent, R.; Goodson, J.M.; Tanner, A.C.R.; et al. The antibacterial effect of photodynamic therapy in dental plaque-derived biofilms. J. Periodontal Res. 2009, 44, 751-759. [CrossRef] [PubMed]

19. Ogura, M.; Abernethy, A.D.; Blissett, R.; Ruggiero, K.; Som, S.; Goodson, J.; Kent, R.; Doukas, A.; Soukos, N.S. Photomechanical wave-assisted molecular delivery in oral biofilms. World J. Microbiol. Biotechnol. 2007, 23, 1637-1646. [CrossRef]

20. Müller, P.; Guggenheim, B.; Schmidlin, P.R. Efficacy of gasiform ozone and photodynamic therapy on a multispecies oral biofilm in vitro. Eur. J. Oral Sci. 2007, 115, 77-80. [CrossRef]

21. Taraszkiewicz, A.; Fila, G.; Grinholc, M.; Nakonieczna, J. Innovative strategies to overcome biofilm resistance. BioMed Res. Int. 2013, 2013, 13. [CrossRef] [PubMed]

22. Shiha, M.-H.; Huang, F.-C. Repetitive methylene blue-mediated photoantimicrobial chemotherapy changes the susceptibility and expression of the outer membrane proteins of Pseudomonas aeruginosa. Photodiagn. Photodyn. Ther. 2013, 10, 664-671. [CrossRef] [PubMed]

23. Danhier, F.; Ansorena, E.; Silva, J.M.; Coco, R.; Le Breton, A.; Préat, V. PLGA-based nanoparticles: An overview of biomedical applications. J. Control. Release 2012, 161, 505-522. [CrossRef] [PubMed]

24. Calixto, G.M.F.; Bernegossi, J.; de Freitas, L.M.; Fontana, C.R.; Chorilli, M. Nanotechnology-based drug delivery systems for photodynamic therapy of cancer: A review. Molecules 2016, 21, 342. [CrossRef] [PubMed]

25. Nakanishia, W.; Minami, K.; Shrestha, L.K.; Ji, Q.; Hill, J.P.; Ariga, K. Bioactive nanocarbon assemblies: Nanoarchitectonics and applications. Nano Today 2014, 9, 378-394. [CrossRef]

26. Ariga, K.; Kawakami, K.; Ebara, M.; Kotsuchibashi, Y.; Jia, Q.; Hillab, J.P. Bioinspired nanoarchitectonics as emerging drug delivery systems. New J. Chem. 2014, 38, 5149-5163. [CrossRef]

27. Abdollahi, S.; Lotfipour, F. PLGA- and PLA-based polymeric nanoparticles for antimicrobial drug delivery. Biomed. Int. 2012, 3, 11-16. 
28. Santos, F.K.; Oyafuso, M.; Kiill, C.; Gremiao, M.P.; Chorilli, M. Nanotechnology-based drug delivery systems for treatment of hyperproliferative skin diseases-A review. Curr. Nanosci. 2013, 9, 159-167. [CrossRef]

29. Souza, A.L.R.; Kiill, C.P.; Santos, F.K.; Luz, G.M.; Rocha e Silva, H.; Chorilli, M.; Gremiao, M.P.D. Nanotechnology-based drug delivery systems for dermatomycosis treatment. Curr. Nanosci. 2012, 8, 512-519. [CrossRef]

30. Santos, B.F.; Gremião, M.P.D.; Chorilli, M. Nanotechnology-based drug delivery systems for the treatment of Alzheimer's disease. Int. J. Nanomed. 2015, 10, 4981-5003. [CrossRef] [PubMed]

31. Sato, M.R.; da Silva, P.B.; de Souza, R.A.; dos Santos, K.C.; Chorilli, M. Recent Advances in Nanoparticle Carriers for Coordination Complexes. Curr. Top. Med. Chem. 2015, 15, 287-297. [CrossRef] [PubMed]

32. Koo, Y.E.L.; Fan, W.; Hah, H.; Xu, H.; Orringer, D.; Ross, B.; Rehemtulla, A.; Philbert, M.A.; Kopelman, R. Photonic explorers based on multifunctional nanoplatforms for biosensing and photodynamic therapy. Appl. Opt. 2007, 46, 1924-1930. [CrossRef] [PubMed]

33. Pagonis, T.C.; Chen, J.; Fontana, C.R.; Devalapally, H.; Ruggiero, K.; Song, X.; Foschi, F.; Dunham, J.; Skobe, Z.; Yamazaki, H.; et al. Nanoparticle-based endodontic antimicrobial photodynamic therapy. J. Endod. 2010, 36, 322-328. [CrossRef] [PubMed]

34. Deng, X.; Liang, Y.; Peng, X.; Su, T.; Luo, S.; Cao, J.; Gua, Z.; He, B. A facile strategy to generate polymeric nanoparticles for synergistic chemo-photodynamic therapy. Chem. Commun. 2015, 51, 4271-4274. [CrossRef] [PubMed]

35. Lucky, S.S.; Soo, K.C.; Zhang, Y. Nanoparticles in photodynamic therapy. Chem. Rev. 2015, 115, 1990-2042. [CrossRef] [PubMed]

36. Kumari, A.; Yadav, S.K.; Yadav, S.C. Biodegradable polymeric nanoparticles based drug delivery systems. Colloid Surf. B 2010, 75, 1-18. [CrossRef] [PubMed]

37. Sah, E.; Sahis, H. Recent trends in preparation of poly(lactide-co-glycolide) nanoparticles by mixing polymeric organic solution with antisolvent. J. Nanomater. 2015, 2015, 22. [CrossRef]

38. Souza, E.; Medeiros, A.C.; Gurgel, B.C.; Sarmento, C. Antimicrobial photodynamic therapy in the treatment of aggressive periodontitis: A systematic review and meta-analysis. Lasers Med. Sci. 2016, 31, 187-196. [CrossRef] [PubMed]

39. Sgolastra, F.; Petrucci, A.; Severino, M.; Graziani, F.; Gatto, R.; Monaco, A. Adjunctive photodynamic therapy to non-surgical treatment of chronic periodontitis: A systematic review and meta-analysis. J. Clin. Periodontol. 2013, 40, 514-526. [CrossRef] [PubMed]

40. Del Pozo, J.L.; Patel, R. The challenge of treating biofilm-associated bacterial infections. Clin. Pharmacol. Ther. 2007, 82, 204-209. [CrossRef] [PubMed]

41. Whiteley, M.; Bangera, M.G.; Bumgarner, R.E.; Parsek, M.R.; Teitzel, G.M.; Lory, S.; Greenberg, E.P. Gene expression in Pseudomonas aeruginosa biofilms. Nature 2001, 413, 860-864. [CrossRef] [PubMed]

42. Brown, M.R.; Allison, D.G.; Gilbert, P. Resistance of bacterial biofilms to antibiotics: A growth-rate related effect? J. Antimicrob. Chemother. 1988, 22, 777-780. [CrossRef] [PubMed]

43. Gilbert, P.; Das, J.; Foley, I. Biofilm susceptibility to antimicrobials. Adv. Dent. Res. 1997, 11, 160-167. [CrossRef] [PubMed]

44. Tegos, G.P.; Masago, K.; Aziz, F.; Higginbotham, A.; Stermitz, F.R.; Hamblin, M.R. Inhibitors of bacterial multidrug efflux pumps potentiate antimicrobial photoinactivation. Antimicrob. Agents Chemother. 2008, 52, 3202-3209. [CrossRef] [PubMed]

45. Nougayrède, J.P.; Kurokawa, K.; Tashiro, K.; Tobe, T.; Nakayama, K.; Kuhara, S.; Oswald, E.; Watanabe, H.; Hayashi, T. Extensive genomic diversity and selective conservation of virulence-determinants in enterohemorrhagic Escherichia coli strains of O157 and non-O157 serotypes. Genome Biol. 2007, 8, R138. [CrossRef]

46. Klepac-Ceraj, V.; Patel, N.; Song, X.; Holewa, C.; Patel, C.; Kent, R.; Amiji, M.M.; Soukos, N.S. Photodynamic effects of methylene blue-loaded polymeric nanoparticles on dental plaque bacteria. Lasers Surg. Med. 2011, 43, 600-606. [CrossRef] [PubMed]

47. McCarthy, J.R.; Perez, J.M.; Bruckner, C.; Weissleder, R. Polymeric nanoparticle preparation that eradicates tumors. Nano Lett. 2005, 5, 2552-2556. [CrossRef] [PubMed]

48. Baeloa, A.; Levato, R.; Julián, E.; Crespo, A.; Astola, J.; Gavaldà, J.; Engel, E.; Mateos-Timoneda, M.A.; Torrents, E. Disassembling bacterial extracellular matrix with DNase-coated nanoparticles to enhance antibiotic delivery in biofilm infections. J. Control. Release 2015, 209, 150-158. [CrossRef] [PubMed] 
49. Forier, K.; Raemdonck, K.; de Smedt, S.C.; Demeester, J.; Coenye, T.; Braeckmans, K. Lipid and polymer nanoparticles for drug delivery to bacterial biofilms. J. Control. Release 2014, 190, 607-623. [CrossRef] [PubMed]

50. Boda, S.K.; Broda, J.; Schiefer, F.; Weber-Heynemann, J.; Hoss, M.; Simon, U.; Basu, B.; Jahnen-Dechent, W. Cytotoxicity of ultrasmall gold nanoparticles on planktonic and biofilm encapsulated gram-positive Staphylococci. Small 2015, 11, 3183-3193. [CrossRef] [PubMed]

51. Iannitelli, A.; Grande, R.; di Stefano, A.; di Giulio, M.; Sozio, P.; Bessa, L.J.; Laserra, S.; Paolini, C.; Protasi, F.; Cellini, L. Potential antibacterial activity of carvacrol-loaded poly (DL-lactide-co-glycolide)(PLGA) nanoparticles against microbial biofilm. Int. J. Mol. Sci. 2011, 12, 5039-5051. [CrossRef] [PubMed]

52. Chronopoulou, L.; Massimi, M.; Giardi, M.F.; Cametti, C.; Devirgiliis, L.C.; Dentini, M.; Palocci, C. Chitosan-coated PLGA nanoparticles: A sustained drug release strategy for cell cultures. Colloids Surf. B Biointerfaces 2013, 103, 310-317. [CrossRef] [PubMed]

53. Bechet, D.; Couleaud, P.; Frochot, C.; Viriot, M.L.; Guillemin, F.; Barberi-Heyob, M. Nanoparticles as vehicles for delivery of photodynamic therapy agents. Trends Biotechnol. 2008, 26, 612-621. [CrossRef] [PubMed]

54. Keawchaoon, L.; Yoksan, R. Preparation, characterization and in vitro release study of carvacrol-loaded chitosan nanoparticles. Colloids Surf. B Biointerfaces 2011, 84, 163-171. [CrossRef] [PubMed]

55. Ungaro, F.; d'Angelo, I.; Coletta, C.; d'Emmanuele di Villa Bianca, R.; Sorrentino, R.; Perfetto, B.; Tufano, M.A.; Miro, A.; La Rotonda, M.I.; Quaglia, F. Dry powders based on PLGA nanoparticles for pulmonary delivery of antibiotics: Modulation of encapsulation efficiency, release rate and lung deposition pattern by hydrophilic polymers. J. Control. Release 2012, 157, 149-159. [CrossRef] [PubMed]

56. Petersilka, G.J.; Ehmke, B.; Flemmig, T.F. Antimicrobial effects of mechanical debridement. Periodontol. 2000 2002, 28, 56-71. [CrossRef] [PubMed]

57. Zijnge, V.; Meijer, H.F.; Lie, M.A.; Tromp, J.A.; Degener, J.E.; Harmsen, H.J.; Abbas, F. The recolonization hypothesis in a full-mouth or multiple-session treatment protocol: A blinded, randomized clinical trial. J. Clin. Periodontol. 2010, 37, 518-525. [CrossRef] [PubMed]

58. Teles, F.R.; Teles, R.P.; Uzel, N.G.; Song, X.Q.; Torresyap, G.; Socransky, S.S.; Haffajee, A.D. Early microbial succession in redeveloping dental biofilms in periodontal health and disease. J. Periodontal Res. 2012, 47, 95-104. [CrossRef] [PubMed]

59. Sanz-Sánchez, I.; Ortiz-Vigón, A.; Herrera, D.; Sanz, M. Microbiological effects and recolonization patterns after adjunctive subgingival debridement with Er:YAG laser. Clin. Oral Investig. 2015. [CrossRef] [PubMed]

60. Novaes, A.B., Jr.; Schwartz-Filho, H.O.; de Oliveira, R.R.; Feres, M.; Sato, S.; Figueiredo, L.C. Antimicrobial photodynamic therapy in the non-surgical treatment of aggressive periodontitis: Microbiological profile. Lasers Med. Sci. 2012, 27, 389-395. [CrossRef] [PubMed]

61. Petelin, M.; Perkič, K.; Seme, K.; Gašpirc, B. Effect of repeated adjunctive antimicrobial photodynamic therapy on subgingival periodontal pathogens in the treatment of chronic periodontitis. Lasers Med. Sci. 2015, 30, 1647-1656. [CrossRef] [PubMed]

62. Teles, R.; Benecha, H.K.; Preisser, J.S.; Moss, K.; Starr, J.R.; Corby, P.; Genco, R.; Garcia, N.; Giannobile, W.V.; Jared, H.; et al. Modelling changes in clinical attachment loss to classify periodontal disease progression. J. Clin. Periodontol. 2016. [CrossRef] [PubMed]

(C) 2016 by the authors; licensee MDPI, Basel, Switzerland. This article is an open access article distributed under the terms and conditions of the Creative Commons Attribution (CC-BY) license (http://creativecommons.org/licenses/by/4.0/). 